\title{
Project management and institutional complexity in domestic housing refurbishment with innovative energy solutions. A case study analysis.
}

\author{
Thomas Hoppe ${ }^{1, *}$, Kris R.D. Lulofs ${ }^{2}$ \\ ${ }^{1}$ CSTM, Institute for Innovation and Governance Studies, University of Twente, Enschede, the Netherlands \\ ${ }^{2}$ CSTM, Institute for Innovation and Governance Studies,University of Twente, Enschede, the Netherlands \\ * Corresponding author. Tel: +31 489 3242, Fax: +31 489 4850, E-mail: t.hoppe@utwente.nl
}

\begin{abstract}
Applying innovative energy solutions (IES) in dense residential areas in the Netherlands is a challenge. This paper presents a typology that supports the analysis and understanding of policy implementation processes to encourage the adoption of innovative energy solutions in urban residential areas. The typology uses theoretical concepts from the social sciences, more specifically the disciplines of public administration and policy studies. The two main hypotheses in the paper are that: (a) a high degree of process management will lead to an increasing likelihood that such a policy will be successful implemented, whereas: (b) a high degree of institutionalized interest from other policy areas - especially urban renewal - will lead to failure to implement policy strategies aimed at the adoption of innovative energy solutions. The hypotheses are empirically tested by presenting four case studies in which fitting innovative energy solutions in domestic housing was on the residential site refurbishment project agenda. The paper adds further insights in the fields of environmental energy policy implementation, sustainable cities and energy transition.
\end{abstract}

Keywords: Environmental energy policy implementation, Urban renewal, Sustainable cities, Housing, Case studies.

\section{Introduction}

Larger energy efficiency can nowadays be achieved in existing dwellings, thanks to longer equipment lifecycles, slow replacement rates, and emerging technical innovations. Opportunities for large-scale energy conservation can thus now be found in neighbourhood revitalization projects [1]. These projects aim at improving the social and physical structure of post-War housing estates in which the houses and their environments are characterized by poor-quality, obsolete physical construction. An additional characteristic is that the poor-quality buildings are accompanied by a poor social structure, as indicated by high unemployment, aboveaverage crime rates and a large proportion of ageing residents. To cope with those problems, neighbourhood revitalization projects are meant to improve both social and physical (construction) structures.

A national government (climate) policy that seeks to link into existing neighbourhood revitalization projects, offers advantages. Such sites contain a large number of dwellings owned by central actors (housing associations) and renovating them will be a major operation in any case, so there will be a low threshold for the house owners to adopt energy conservation measures. Local governments encourage the setting of ambitious goals as a stepping stone to realize high energy efficiency goals [1]. Improving energy efficiency proves to be a difficult task, though. Due to the absence of legal governmental instruments there is a need to rely on communicative and economic policy instruments to convince house owners and stakeholders. Moreover, only 'soft instruments' are used, such as information campaigns, covenants and subsidy schemes [2]. This means that governments are dependent on the willingness of their target groups. Although the description applied to the Dutch situation, it is similar to those encountered in other Western European countries [3].

Local governments are able to exercise influence and encourage the uptake of energy conservation appliances by making trade-offs with housing associations, with a strategic use 
of urban renewal subsidies and legal permits. However, the local authorities remain firmly dependent on the willingness of housing associations and other property owners to cooperate. Lengthy and complex decision-making is unavoidable when a large-scale neighbourhood or building block renovation plan is being scheduled. In short, many institutional barriers exist that prevent the large-scale adoption of technical appliances to stimulate energy efficiency in existing housing [2].

The analytical focus in this paper is on the adoption of energy innovations in projects in which family dwellings are refurbished. The central question of the paper is how to understand and overcome the difficulties that adoption of energy innovations encounters in neighbourhood revitalization projects in urban residential areas. A typology based on theoretical insights derives from network governance and institutional complexity is introduced to support further comprehension. The typology is designed to improve analysis of complex contexts in which energy innovations - especially renewable energy systems - are adopted in highly institutionalized contexts, such as large-scale refurbishment projects in post-War urban residential areas.

\section{Theoretical framework}

Here we discuss the need to design a new typology to better understand the adoption of energy systems in a highly institutionalized context. The theoretical literature on environmental policy integration is presented as well as governance mechanisms to deal with complexity in similar contexts, drawn from the literature in the disciplines of public administration and policy studies of the management of complex networks, the aim being to achieve collective policy objectives in multi-stakeholder settings. The section ends with the introduction of a typology that covers two dimensions: (1) institutional complexity (as a lack of policy integration) and (2) project management of complex situations.

\subsection{Institutional complexity}

Environmental policies and energy efficiency goals are not prioritized in major urban settings. Moreover, social and economic aspects of the living environment and the climate for attracting business enterprises are often considered more important. Furthermore, environmental energy objectives may not be fully integrated or coordinated with other policy domains' objectives which also need to be fulfilled in such projects. This is no wonder since problems related to climate change - an environmental problem "at large" [4] - are not limited to a single sector or policy domain and hence are not coordinated optimally. This calls for environmental policy integration [5] - balancing the interests, concerns and priorities of the so-called three pillars: social, economic and environmental dimensions [6] - or arenas in which policy sectors are not competing for attention on the agenda, but which rather converge [7]. In many domains this is not yet the case [5, 8], such as revitalization of post-War neighbourhoods, a domain subject to urban renewal policy. These neighbourhoods are characterized by factors that hamper effective decision-making, such as distributed ownership rights, high 'social infrastructure', and hence complex regulations. For instance, regulation which requires tenants' approval to the project plans in large scale refurbishment projects. To deal with these complex issues many local revitalization projects receive earmarked financial support from government. In turn, local stakeholders are requested to ensure that the project meets urban renewal performance targets. Energy efficiency is no longer considered a significant target in urban renewal practice, at least not in the Netherlands. 


\subsection{Project management}

Realizing the installation of innovative energy systems in local neighbourhood revitalization projects meets complexity in decision-making as multiple actors are involved who have interests and are mutual dependent. Actor-networks dominate negotiations and bargain about how to meet public goals. From a governmental perspective 'steering' towards the achievement of public goals, such as reductions in greenhouse gas emissions, then becomes a difficult task. In this regard, management of decision-making in a multi-actor setting becomes important. Due to the presence of multiple interconnected actors this can be perceived as 'governance of complex networks' [9]. Management of such public-private networks cannot be perceived as just a form of governmental 'steering' which has a broader meaning than strict, administrative control. Given the context, it may be better to define it more accurately as "directed influence" rather than steering [9]. The challenge, rather, is to realize policy in interaction with those other actors, which can engage social support, withstand the test of criticism, and connect other actors to policy efforts. Public agencies therefore fulfil the role of safeguarding that under-represented goals - such as environmental ones - and interests can participate in games. In a multi-actor, decision-making game this requires a balancing act if the actors involved are to achieve the goal(s) successfully and simultaneously [9]. It enables their perceptions to be aligned, visions to be converged, expectations to be discussed, mutual trust to be created, sharing of experiences (especially tacit knowledge), with reflection on how to achieve goals in a feasible manner, and keep environmental goals on the decision-making agenda. This requires a custom approach which fits the particular setting and its actors, for instance by gathering support from stakeholders to facilitate effective decision-making. In such settings, public actors may function as 'network managers': they may act as a 'facilitator' or 'process manager' by facilitating dialogues between actors and employ techniques such as workshops and brainstorming sessions to promote consensus building. By doing this they may attract skilled participants, and gather external resources (such as subsidies or loans), which enables professional leadership and favours learning conditions. Other game management strategies are: covenanting, influencing actor's perceptions, bargaining, introduction of ideas in furtherance of reflection, selective activating of actors (usually not present in the arena), furtherance of facilitation, brokerage, and mediation [9]. In the domain environmental energy 'change agents' [10] aim to have multiple actors adopt green energy technologies [11].

\subsection{A typology}

Based on the two dimensions introduced in the previous sections, a two-dimensional typology is adduced. The matrix has four quadrants, allowing predictions to be made concerning the outcome of the project's objectives on the adoption of energy innovations. A graphical presentation of the typology is presented in figure 1 . The dimension "institutional complexity" is presented on the vertical axis, with the dimension "project management" on the horizontal one. In this study the unit of observation of the typology relates to neighbourhood refurbishment projects in urban residential areas. Besides application to the issue discussed here, the typology may also be applicable to other types of projects with multiple actors, interdependent actors that seek to achieve (collective) goal(s).

The two hypotheses relevant to the dimensions in the typology are that: (a) a high degree of process management will lead to an increasing likelihood of successful adoption of energy innovations by project stakeholders: whereas (b) a high degree of institutionalized complexity - from other policy domains, especially urban renewal - will lead to failure in the implementation of policy strategies aimed at the adoption of innovative energy systems. 
The main hypothesis of this paper concerns a combination of these two hypotheses. On the basis of these propositions expectations can be formulated about the influence of the dimensions in terms of four possible outcomes. This is shown in figure 1 . Whereas the optimum outcome can be expected in quadrant $4\left(\mathrm{Q}_{4}\right.$; low institutional complexity and a high degree of project management), the worst outcome can be expected in quadrant $1\left(\mathrm{Q}_{1}\right.$; high institutional complexity and low degree of project management). The outcomes in quadrants 2 and 3 will lie between the extreme outcomes in quadrants 1 and 4 .

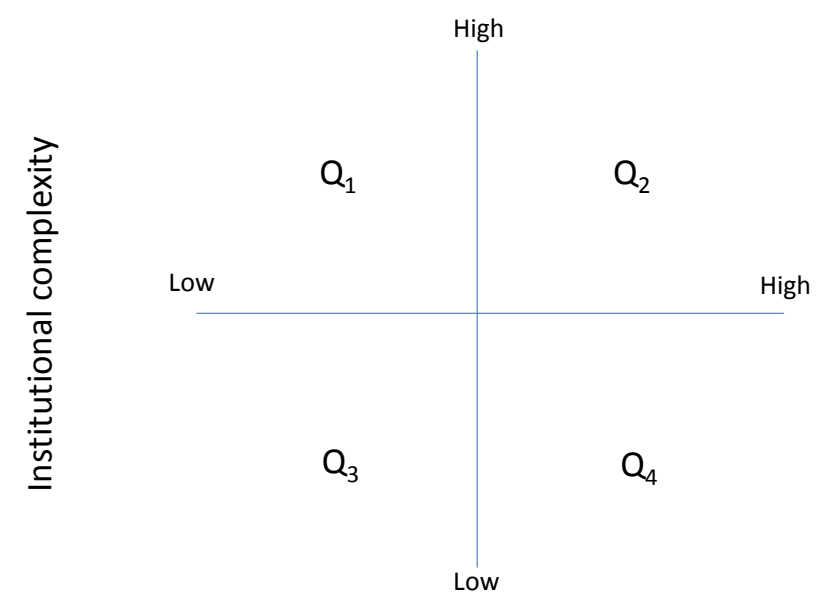

Project management

Fig. 1. Graphical representation of the typology.

\section{Methodology}

The empirical study comprised four case studies concerning residential district renovation projects that featured family housing. The cases were selected from an existing project set that provides information on urban renewal projects and ambitions for energy affairs [12]. The four case study projects all comprise domestic housing built in the late 1960's and early 1970’s.

Different types of data were collected, both qualitative and quantitative. Among other things, 27 semi-structured interviews were conducted. Additional documentation on the cases was traced both before and after the interviews were conducted. The project documents retrieved included formal policy documents, advisory reports, annual reports, other informative papers, websites, feasibility study reports and geographical maps of project locations. Data were collected between October 2007 and April 2008.

In this study, a cross-case (comparative) research design was applied. The analysis was conducted in order to test the predictions based on the main hypothesis following the typology in the previous section. The dimensions 'project management' and 'institutional complexity were operationalized as 'ten-point-Lickert-scales. For the analysis the scores-per-case were assigned to the scales on the two dimensions. Next, the positions of the cases were plotted in a graphical display on the basis of the two-dimensional typology. 


\section{Results}

In table 1 key data on the cases studies are presented. The table presents information on the initial objective (ambition) during the early stages of the project and actual outcome (in terms of innovative energy systems being applied). As it turns out, in three out of four cases no innovative energy systems were applied.

Table 1. Key data on four case studies.

\begin{tabular}{llll}
\hline Name of site & $\begin{array}{l}\text { Name of } \\
\text { town }\end{array}$ & IES (ambition) & $\begin{array}{l}\text { IES (actually } \\
\text { implemented) }\end{array}$ \\
\hline Atol- en Zuiderzeewijk & Lelystad & None & $\begin{array}{l}\text { None; only } \\
\text { conventional } \\
\text { measures }\end{array}$ \\
Bijvank en het Lang & Enschede & Solar thermal system & $\begin{array}{l}\text { None; only } \\
\text { conventional } \\
\text { measures }\end{array}$ \\
Nieuwstad & Culemborg & $\begin{array}{l}\text { Solar thermal } \\
\text { systems or district } \\
\text { heating from an } \\
\text { industrial plant }\end{array}$ & $\begin{array}{l}\text { None; only } \\
\text { conventional } \\
\text { measures }\end{array}$ \\
& & $\begin{array}{l}\text { Collective biomass } \\
\text { installations and heat } \\
\text { pumps }\end{array}$ & Passive renovation \\
Groot Kroeven & Roosendaal & \\
\hline
\end{tabular}

Figure 2 presents the result of the comparative analysis of the case studies. The positions of the cases in the figure relate to the scores on both dimensions 'institutional complexity' and 'process management', presented in a scatter plot. As can be seen, the cases in which a high degree of project management and a low degree of institutional complexity are present, innovative energy systems have been applied in existing apartment buildings. This is to say that the case in quadrant 4 (Groot Kroeven) has a positive outcome, as was predicted by the main hypothesis in section 2.3. The other cases, situated in quadrants 1 (Atol- en Zuiderzeewijk), 2 (Bijvank en het Lang) and 3 (Nieuwstad) have negative outcomes.

\subsection{Discussion}

The results of the analysis allow lessons to be drawn. First, in all four cases innovative energy systems were not applied, and in the cases in which innovative energy systems were initially considered the initial objectives were not met. During the project trajectories plans were changed for different reasons. Only the refurbishment project in the Groot Kroeven case may be considered successful. Although the institutional complexity conditions favoured success the local government did not own property near the site and no serious urban renewal performance targets focused on the project - the outcome was to a large extent due to clever project management. This resulted from a combination of professional leadership, an actornetwork of motivated and skilled participants, a high level of trust between the stakeholders, the use of subsidies, and learning capacity. This last point was revealed as initial barriers were overcome. This came at a high price, though, as expertise and personnel capacity had to be hired from abroad, new construction measures had to be designed and tested - in fact 
experimental houses were established and monitored -, and a difficult decision-making process had to be undertaken to convince tenants and thus to meet the legal '70 percent tenant-approval standard' for large-scale refurbishment projects. All these matters led to delay in the project schedule. Hence, additional costs were incurred. Nonetheless, the infrequently used concept of "passive renovation" was applied successfully in 134 houses. The initiative to adopt this innovative concept had its origin in the housing association (or actually the project manager in situ), not the local authority.

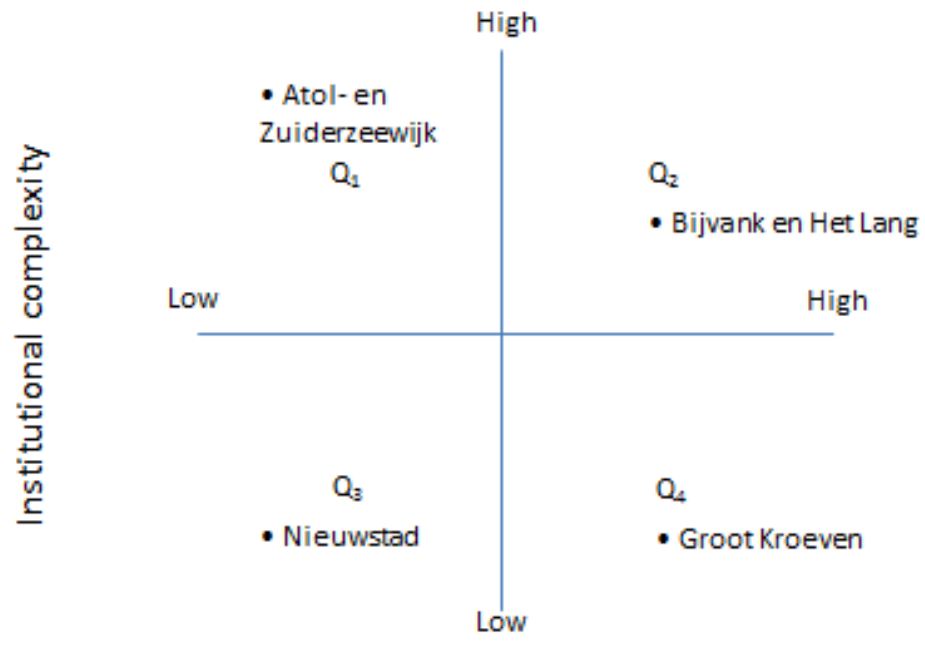

Process management

Fig. 2. Results of the case study analysis.

Second, if one's aim is to fit innovative energy solutions in renovation projects with a high degree of complexity, one is prone to encounter problems. When the housing property owner does not have the financial means to invest, on-site housing ownership rights are distributed among many different actors, and urban renewal objectives are given priority, the chances of successfully applying energy innovations are poor. The cases Atol- en Zuiderzeewijk and Bijvank en het Lang provide evidence that non-energy related urban renewal issues are assigned greater importance in the projects. When considered during the initial stages, the innovative energy appliance became an 'end of the bill' objective and was dropped from the agenda when cost estimations were done, and tenants feared monthly rent increases and delays to the project. The latter also applies to the Nieuwstad case.

Third, the cases revealed mistrust between the actors involved. Local authorities initiated a process to have energy innovations applied in local housing projects. They managed to have an energy audit report drafted by an external consultancy agency (paid for with a subsidy from national government). The advice in the audit report considered several options for onsite improvements to energy-efficiency. However, they were met with scepticism by the project stakeholders, especially the housing associations. To a large extent this related to the credibility of the energy audit reports. A difficulty, when the energy audit advice was taken into consideration, was that it remained on the decision-making agenda, especially when the actual costs of installing the systems were looked at. When the actual calculations were done it turned out that the audit report advices left out significant cost aspects, such as the installing costs and the replacement of energy-infrastructure (pipelines), as shown by Bijvank en het Lang and Nieuwstad cases. 
In two cases (Bijvank en het Lang, and Nieuwstad) the housing associations complained about the unequal distribution of costs between stakeholders in the revitalization project in respect of the use of innovative energy solutions. Whereas the local authority aimed at having renewable energy systems, it did not participate in sharing in the costs. As a consequence, the housing associations were to bear the costs single-handedly, which was considered demotivating. These two cases show that it is very important that local government and housing associations discuss a project plan seriously in the project's initial stages. In both cases the housing associations blamed the local governments for their high ambitions but their unwillingness to share in the additional costs, which bred mistrust. In that sense, it was no surprise that the ambitious energy objectives failed as the housing associations were confronted with the high costs of installing the systems, once they were seriously considered and calculated. Ergo, due to non-specific negotiations between the two parties in the initial stages of the projects, the financial feasibility of the objective was never discussed in detail.

Fourth, it may be stated that the cases show that energy innovations are preferably installed in projects that feature newly constructed houses rather than the renovation of existing houses (which means that one needs to cope with social and institutional 'infrastructure'). Theoretically speaking, new construction is favoured by the opportunity to make high investments for the long term, which needs to be done anyway, plus the absence of an existing energy infrastructure. This may also be the reason why the municipality of Lelystad - a national renewable energy frontrunner - did not formulate an ambition for the renovation of the existing neighbourhood Atol- en Zuidzeewijk, whereas there were many recently built residential sites nearby with innovative energy systems (wind power and district heating).

Finally, the cases also provide evidence that tenants fear innovative energy solutions. When requested in a vote, tenants did not accept an increase in their monthly rents as compensation for having a solar thermal system installed in their houses. The outcome of the vote was a reason for housing association to renounce the option of having the renewable energy system used in the project. The tenants' fear may have a background in their unfamiliarity to innovative systems, but may also be related to mistrust between the tenants and the housing association.

\section{Conclusion}

The installation of innovative energy solutions in urban areas is difficult, as local neighbourhood revitalization projects are highly complex. This paper has introduced a typology to support the analysis and understanding of local projects in which energy innovations are to be fitted. We used a comparative case study research design to test the predictions empirically against the typology. The research design comprised four case studies of local neighbourhood revitalization projects in the Netherlands, concerning refurbishment of domestic housing. The main hypothesis was confirmed as success as predicted only concerned a local project where a low degree of institutional complexity was combined with a high degree of project management.

This case, the Groot Kroeven project, shows that due to a combination of clever project management, professional leadership, learning capacity, an actor-network of motivated and skilled participants, the use of subsidies, and the absence of highly demanding urban renewal context and -project plans, barriers were overcome and positive project outcomes can be realized. 
The external validity of the results is limited due to the few amounts of cases we were able to investigate. A case study design - with only four cases - was necessary, though, due to the need to analyse detailed data, which are difficult to collect and require many efforts. More research is necessary to apply our typology and to test its main hypothesis in research designs that feature more observations. This could very well be possible in other contexts, such as different types of buildings, neighbourhoods or geographical entities. One may consider applying the typology to challenges that impede the achievement of 'sustainable cities'.

\section{References}

[1] T. Hoppe, J. Bressers and K.Lulofs, Local Government Influence on Energy Conservation Ambitions in Existing Housing Sites - Plucking the Low-hanging Fruit?, Energy Policy, 2011, 39, pp. 916-925.

[2] T. Hoppe, and K. Lulofs, The Impact of Multi-level Governance on Energy Perfomance in the Current Dutch Housing Stock, Energy \& Environment, 19(6), pp. 819 - 830.

[3] M. Elle, T. van Hoorn, T. Moss, A. Slob, W. Vermeulen, and J. van der Waals, J. Rethinking Local Housing Policies and Energy Planning: The Importance of Contextual Dynamics. Built Environment, 28(1), pp. 46-56.

[4] M. Hajer, The Politics of Environmental Discourse: Ecological Modernisation and the Policy Process. Clarendon Press, 1995.

[5] EES, "Environmental Policy Integration in Europe: State of Play and an Evaluation Framework”, EEA Technical Report, European Environment Agency, 2005.

[6] J. Knudsen, Environmental Policy Integration and Energy, Ph.D. thesis, University of Twente, 2009.

[7] H. Lovell, H. Bulkeley and S. Owens. Converging Agendas? Energy and Climate Change Policies in the UK. Environment and Planning C: Government and Policy 27, 2009, pp. 90-109.

[8] A. Jordan and A. Lenschow, Environmental Policy Integration: an Innovation in Environmental Policy? In A.J. Jordan and A. Lenschow (Eds.). Innovation in Environmental Policy? Integrating the Environment for Sustainability. Cheltenham, UK: Edward Elgar, 2008, pp. 313-341.

[9] W. Kickert, E-H. Klijn and J. Koppenjan. Managing Complex Networks; Strategies for the Public Sector, Sage Publications, 1997.

[10]E. Rogers, Diffusion of Innovations, Third Edition, The Free Press, 2003.

[11]J. van der Waals, W. Vermeulen, and P. Glasbergen, Carbon dioxide reduction in housing: experiences in urban renewal projects in the Netherlands, Environment and Planning C: Government and Policy 21, 2003, pp. 411-427.

[12] T. Hoppe, $\mathrm{CO}_{2}$ reductie in de bestaande woningbouw; een beleidswetenschappelijk onderzoek naar ambitie en prestatie, Ph.D. thesis, University of Twente, 2009. 